\title{
1 Sex, Gender, and Diversity Analysis in Research Policies of Major Public Granting
}

2 Agencies: A Global Review

Lilian Hunt ${ }^{1}$, Londa Schiebinger $* 2,3$

5

${ }^{1}$ Equality, Diversity and Inclusion in Science and Health (EDIS); Culture, Equity, Diversity, and 7 Inclusion, Wellcome Trust, UK

$8 \quad{ }^{2}$ History of Science, Stanford University, USA

$9 \quad{ }^{3}$ Director, Gendered Innovations in Science, Health \& Medicine, Engineering, and Environment 10 *schiebinger@stanford.edu

\section{Abstract}

13 National research agencies are funded by taxpayer monies and, as such, are responsible for

14 promoting excellent research that benefits all of society. Integrating sex, gender and diversity

15 analysis (SG\&DA) into the design of research, where relevant, can improve research

16 methodology and provide new insights. To realize this potential, funding agencies have

17 developed policies for integrating this type of analysis into the grant proposal process. This study

18 reviews those policies for 23 agencies across six continents. Overall, one agency achieved

19 superior performance, six agencies scored excellent performance, five showed average

20 performance, two need some improvement and nine require improvement. Our study developed a

21 five-part SG\&DA policy roadmap for agencies and collected best practices across that guide.

22 Standard practices, tailored as appropriate to country-specific cultures and regulatory landscapes,

23 will enhance collaboration potential, global equity, research excellence and reproducibility.

\section{Introduction}

26 Flawed research costs lives and money, and can lead to inequitable outcomes. Integrating sex,

27 gender and diversity analysis (SG\&DA) into the design of research, where relevant, can improve research methodology, enhance excellence in science and make research more responsive to social needs ${ }^{1}$. To realize this potential, funding agencies have begun implementing policies for

30 integrating this type of analysis into the grant proposal process. In 2003, the European

31 Commission (EC) endorsed 'questioning systematically whether, and in what sense, sex and 
32 gender are relevant in the objectives and methodology of projects' ${ }^{2}$. Other public-funding

33 agencies followed suit with policies implemented at the Canadian Institutes of Health Research

34 (2010), U.S. National Institutes of Health (2016), German Research Foundation (2020), National

35 Research Foundation of Korea (2020), among others.

37 Funding agencies are one of three pillars of the science infrastructure that need to coordinate

38 policies to achieve excellence in science; agencies can encourage integrating SG\&DA at the

39 beginning of research ${ }^{1}$. Pillar two, universities and research institutions, are responsible for

40 developing methods for this type analysis and for providing this expertise to future generations.

41 While faculties of humanities and social sciences typically include sex, gender and diversity

42 analysis in their curricula, many faculties of science, medicine and engineering fall short of

43 integrating knowledge of SG\&DA into their core curricula ${ }^{3}$. Pillar three, peer-reviewed journals,

44 increasingly do so at the end when selecting manuscripts for publication ${ }^{4,5}$. The Lancet and

45 Nature, for example, have implemented such policies ${ }^{6,7}$.

47 Several national funding agencies plus the EC have reviewed their policies for integrating sex 48 and gender analysis into research design ${ }^{8-12}$. One study, by the Global Research Council's

49 Gender Working Group, included questions about these policies in their larger survey on gender-

50 disaggregated data collection among their 128 member organisations. Overall, 65 agencies

51 responded. Of these, $23 \%$ collected data on the number of funded projects that include a gender

52 dimension, $15 \%$ collected data on sex and gender considerations in research design and 9\%

53 collected data on sex and gender considerations in dissemination of research ${ }^{13}$. The Gender

54 Working Group, however, did not assess the quality of these policies. The Swedish Secretariat

55 for Gender Research also conducted a global review, with 28 agencies responding. They found

56 that agencies tended to confuse gender balance in teams with gender analysis in research

$57 \operatorname{design}^{14}$.

59 This study reviews SG\&DA policies of 23 national public granting agencies across five global

60 regions. Our purpose is to provide a global map of best practices in agency policies and

61 processes, and to provide a framework for funders as they develop policies to ensure

62 international standards of excellence. Our results are divided into five sections: definitions of 
63 terms, instructions for applicants, instructions for evaluators, trainings provided to applicants, 64 evaluators and staff, and agency evaluation of policy implementation. Our goal is to help

65 standardize international policies in this area while being sensitive to country-specific cultural 66 differences and regulatory landscapes.

67

\section{SG\&DA Policy Roadmap and Agency Performance}

69 Based on a literature review and prior research ${ }^{15}$, we developed an instrument, consisting of a

70 five-part guide for evaluating successful funding agency policy for SG\&DA in research design

71 (Fig. 1). We convened an international advisory group (Supplementary Information section 1)

72 that included representatives from public funders, expert researchers and policy specialists to

73 discuss and improve the roadmap's clarity, specificity and applicability. 


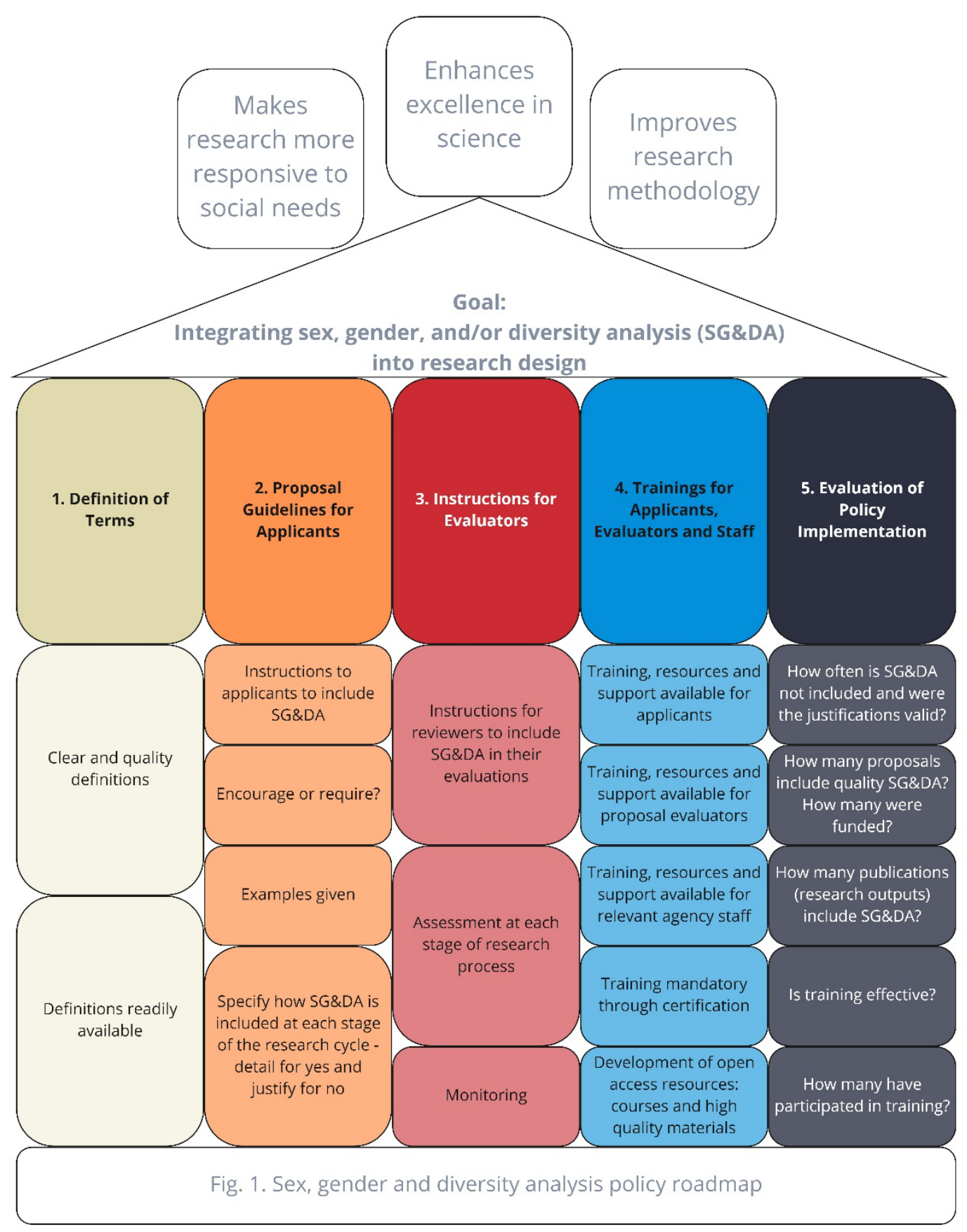

76 We tested our framework through a pilot study of six funding agencies: the Canadian Institutes 77 of Health Research (CIHR), EC, German Research Foundation (DFG), Irish Research Council

78 (IRC), National Research Foundation of Korea (NRF) and US National Institutes of Health

79 (NIH). Through an iterative process, we refined both the instrument and the scoring matrix. 
81 We invited 34 additional funding agencies to participate. In consultation with our advisory

82 board, we selected countries based on geographic spread with the goal of including agencies

83 from all continents that host such agencies. To maintain a global balance we limited the number

84 of European funders invited. Only major publicly funded granting agencies at the national level 85 were eligible. Of the 34 invited, 17 agreed, yielding a final sample of 23 agencies (Table 1).

\begin{tabular}{|l|l|l|l|l|l|}
\hline Region & $\begin{array}{l}\text { Invited } \\
\text { funders }\end{array}$ & $\begin{array}{l}\text { Proportion } \\
\text { of invited } \\
\text { funders }\end{array}$ & $\begin{array}{l}\text { Participating } \\
\text { funders }\end{array}$ & $\begin{array}{l}\text { Proportion } \\
\text { of } \\
\text { participating } \\
\text { funders }\end{array}$ & Response rate \\
\hline $\begin{array}{l}\text { Europe and } \\
\text { Central Asia }\end{array}$ & 14 & $35.0 \%$ & 9 & $39.1 \%$ & $64.3 \%$ \\
\hline $\begin{array}{l}\text { Africa and } \\
\text { Middle East }\end{array}$ & 11 & $27.5 \%$ & 3 & $13.0 \%$ & $27.3 \%$ \\
\hline $\begin{array}{l}\text { South \& East } \\
\text { Asia and Pacific }\end{array}$ & 7 & $17.5 \%$ & 4 & $17.4 \%$ & $57.1 \%$ \\
\hline North America & 5 & $12.5 \%$ & 5 & $21.7 \%$ & $100.0 \%$ \\
\hline $\begin{array}{l}\text { Latin America } \\
\text { and Caribbean }\end{array}$ & 3 & $7.5 \%$ & 2 & $8.7 \%$ & $66.7 \%$ \\
\hline Total & $\mathbf{4 0}$ & \multicolumn{2}{|l}{} \\
\cline { 1 - 4 }
\end{tabular}

87 Table 1. Global spread of participating agencies

89 Funders were invited to complete an online questionnaire and provided a detailed guidance note

90 (invitation, Supplementary Information section 2; questionnaire, section 3; guidance note,

91 section 4). Agencies were required to provide evidence (either publicly available or internally

92 agreed upon) for each answer. Each agency was scored by two evaluators (scoring matrix,

93 Supplementary Information section 5). All scores are confidential to funders and reported here

94 only in aggregate. 
96 Overall, one agency achieved Superior Performance, six agencies scored Excellent Performance,

97 five showed Average Performance, two Need Some Improvement and nine Require

98 Improvement (Fig. 2).

99

100

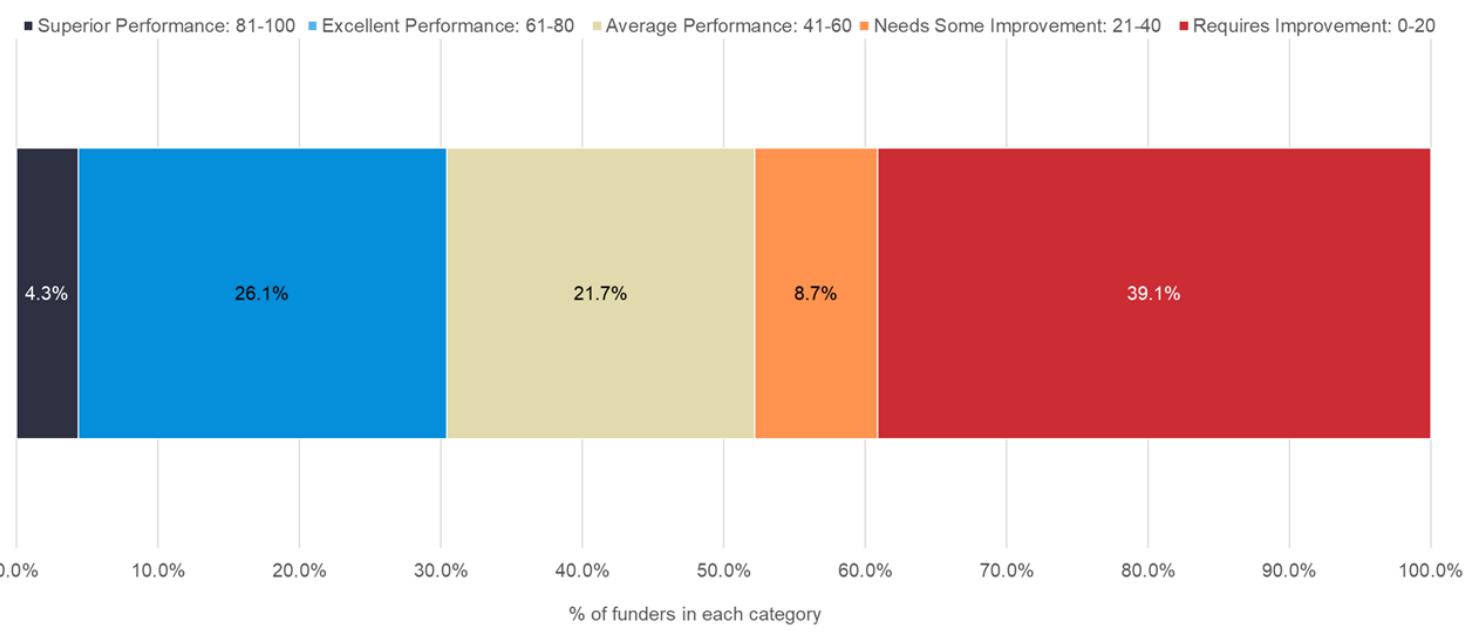

102 Fig 2. Agencies per scoring bracket. Almost half of the agencies studied require improvements 103 to their SG\&DA policies.

104

105 Agencies in Europe, North America and Asia/Pacific were among the highest scorers (Fig. 3).

106 Across all global areas, almost half of agencies provided quality definitions of terms (44\% were

107 in the Excellent/Superior Performance category). Similarly, almost half of agencies have some

108 form of proposal guidelines for applicants. Section five, evaluation of policy implementation,

109 was the weakest, with only $9 \%$ of agencies scoring in the Excellent Performance category and

110 none in the Superior category (Supplementary Information section 6). 


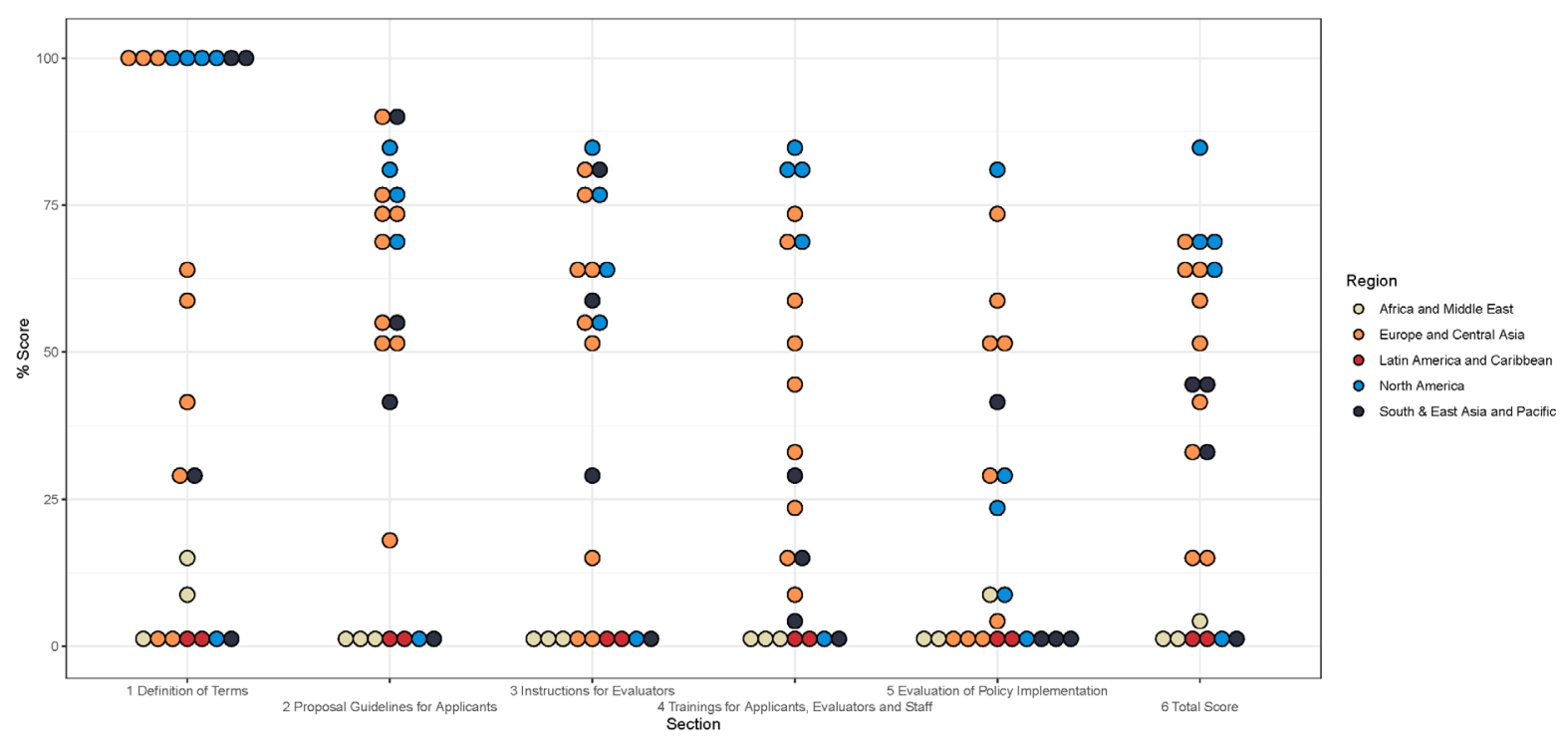

113 Fig. 3. Agency scores across the five assessed sections, by region.

114

115 One complicating factor in comparing agencies is that some agencies span all fields of the

116 human and natural sciences, technology, and health and biomedicine while others focus

117 exclusively on health and biomedicine, the social sciences or humanities. When we divided our

118 data by agency type, we found no striking differences, suggesting that funders with wide remits

119 can successfully implement these policies (Fig. 4).

120

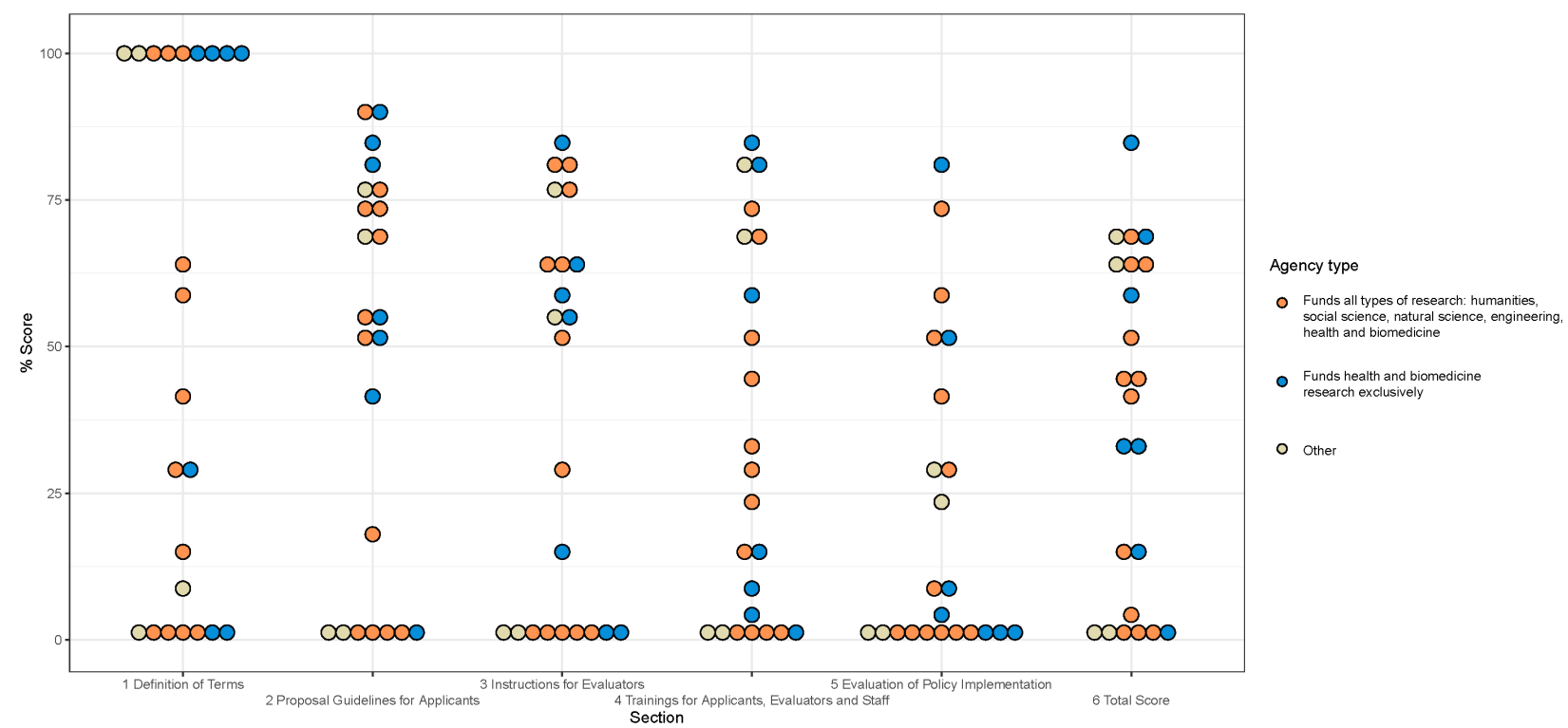

122 Fig. 4. Agency scores across the 5 assessed sections, by type of funding. 


\section{Emerging Best Practices}

125 Here we explore key considerations for each part of our SG\&DA policy roadmap and highlight

126 leading-edge policies that may serve as models.

\section{Definition of terms}

129 The first step in policy development is clear definition of terms. We chose to evaluate agencies 130 on 'sex' and 'gender' analysis because sex and gender were historically the categories included

131 in agency policy, for example, by the EC. While sex is a biological characteristic of humans and 132 numerous non-human organisms and is an important category to continue to call out, gender is at

133 the same epistemic level as other aspects of sociocultural diversity. We privilege gender here

134 because most agency policy include this term, and this allowed us to evaluate developed policy 135 practices. Second, we considered evaluating on intersectional analysis but, after policy reviews 136 and consultation with our advisory board, judged diversity a more generally used term.

Different countries have different regulatory landscapes and axes of historical discrimination.

139 This will influence each agency's choice of which diversity characteristics to prioritize. Funders

140 are increasingly moving beyond sex and gender to include other categories of diversity. Some 141 agencies, such as those in Australia, use guidelines set through national legislation as drivers for 142 updating definitions ${ }^{16}$. We would expect an intersectional approach across sociocultural aspects 143 of diversity.

145 In this section, we evaluated: a. whether agencies have clear definitions for sex, gender, other 146 diversity or intersectional characteristics; and b. whether these definitions were easily found. It is

147 important that the same definitions are shared with applicants, evaluators and staff to support 148 consistency across the agency. For example, the Canadian Tri-Agency (CIHR, Natural Sciences 149 and Engineering Research Council of Canada (NSERC) and Social Sciences and Humanities

150 Research Council) provides web portals and guidance in both English and French describing 151 Gender-Based Analysis Plus (GBA+) that links across agency materials ${ }^{17-22}$.

153 Agencies seeking model definitions of key terms can find peer-reviewed definitions of sex, 154 gender, intersectionality and race \& ethnicity on the Gendered Innovations website ${ }^{23}$. This 
155 resource has been developed, since 2011, in collaboration with the EC. Other model definitions 156 of sex and gender are available at the $\mathrm{NIH}^{24}$ and sex, gender and intersectionality at $\mathrm{CIHR}^{25-27}$.

\section{Proposal guidelines for applicants}

159 Agencies take four basic approaches in their request to applicants to integrate SG\&DA into their 160 proposal, where relevant: most encourage applicants to integrate SG\&DA; some flag research 161 areas where this type of analysis is expected; a few require this type of analysis; some only 162 encourage applicants but instruct evaluators to score this element, making it de facto mandatory.

163 In this study, more points were awarded to funders who required SG\&DA; however, more 164 research is needed to determine the differential impact of these various approaches. In all cases, 165 the 'where relevant' is crucial. No agency asks for SG\&DA in pure mathematics, for example, where no body of literature has established its relevance.

The trajectory of the EC is of interest. Since 2003, the Commission has encouraged sex and gender analysis, referred to as the 'gender dimension', in research. To strengthen the policy, Horizon 2020 in 2014 flagged topics for which taking the gender dimension into account was mandatory. Since 2021, Horizon Europe requires all proposals to consider sex, gender and

172 intersectional analysis in research, unless otherwise specified. The Horizon Europe Programme

173 Guide states: 'the integration of the gender dimension into research and innovation

174 content... becomes a requirement by default... unless the non-relevance for a specific topic is

175 specified [by the Commission] in the topic description'28.

177 The US NIH have, since 2016, required all applicants to consider 'sex as a biological variable'

178 (SABV) and have published peer-reviewed articles detailing how this type of analysis supports

179 good science ${ }^{29,30}$. This requirement supplements policies for inclusion in clinical trials launched

180 in the 1990 s that focused on sex/gender, race and ethnicity ${ }^{31,32}$ and, in clinical research, age

181 (Inclusion Across the Lifespan ${ }^{33}$ ) added in 2019.

183 The DFG implemented its SG\&DA guidelines in 2020 after a two-year consultation and study

184 period. They read, 'researchers examine whether and to what extent gender and diversity

185 dimensions may be of significance to the research project (with regard to methods, work 
186 programme, objectives, etc.) ${ }^{34}$. The DFG does not require applicants to address SG\&DA,

187 emphasizing that it funds 'proposals in curiosity-driven basic research' in fields selected by

188 applicants where freedom of research is $\operatorname{core}^{35}$. In the evaluation process, however, reviewers are

189 instructed to take SG\&DA into account. Similar to the EC, the DFG scores SG\&DA under the

190 'excellence' or 'intellectual merit' criteria for research design.

192 Many funding agencies set policy through national legislation. In Japan, the government renews

193 both the basic plans for Science, Technology and Innovation (STI) and Gender Equality (GE)

194 every five years. In 2020, the sixth STI Basic Plan and the fifth GE Basic Plan both included

195 integrating the gender perspective and gender analysis into research and technology

196 development ${ }^{36,37}$. In 2021, the Republic of Korea passed the Amendment of the Framework Act

197 on Science and Technology to include integrating sex and gender into research ${ }^{38}$. This

198 strengthened the Korean NRF's funding policy for research that promotes national economic

199 development and the quality of citizens' lives.

Agencies provide instructions to applicants in various ways. Some funders provide checklists ${ }^{39}$

202 or key questions ${ }^{40}$ to help applicants decide whether SG\&DA is relevant for their research.

203 Others provide separate FAQs ${ }^{41}$ or include a description ${ }^{42}$ of what is expected in the overall

204 research. Still others include a mandatory open-ended text box on the submission form for

205 applicants to indicate how SG\&DA is integrated into the proposal or to justify its exclusion ${ }^{8}$. In

206 our study, we evaluated whether applicants are instructed to detail how SG\&DA analysis is

207 incorporated into all phases of research — from establishing project objectives to developing

208 methodologies, gathering and analysing data, to evaluating and reporting results ${ }^{43,44}$. If SG\&DA

209 is not relevant to the proposed research, applicants should be asked to provide literature to

210 demonstrate that no sex, gender or other relevant differences have been found ${ }^{8}$.

\section{Instructions for evaluators}

213 Evaluators are crucial to the success of these policies. To be successful, agencies must instruct

214 evaluators to consider sex, gender and/or diversity analysis across all stages of the research

215 process. CIHR found that 'targeting applicants alone to adopt new sciences policies without 216 concomitant pressure by evaluators...may not be effective ${ }^{8}$. Since 2018, CIHR has required 
217 evaluators to rate the quality of the SG\&DA as a 'strength', 'weakness' or 'not applicable' and to

218 provide a rationale for their rating along with recommendations to applicants for improvement.

220 Funders should provide applicants and evaluators similar forms and instructions for consistency

221 across the research process. Some agencies, such as the EC, are limited in the overall instructions

222 they can provide on this particular requirement given the number of topics that need to be

223 covered. Agencies may provide 'good research guides' that reference assessing SG\&DA

224 alongside other elements of peer review, such as ethics and reproducibility ${ }^{34}$.

226 Agencies must monitor the evaluation process to confirm that SG\&DA is addressed in reviewer 227 comments and that those comments are high quality. CIHR, for example, samples $5 \%$ of

228 reviewer rationale for their SG\&DA ratings ${ }^{8}$.

\section{Trainings for applicants, evaluators and staff}

231 SG\&DA is not yet consistently part of university curricula in the physical and life sciences,

232 health and biomedicine, and engineering. Until universities step up to the task, funding agencies 233 need to fill this gap.

235 Some funding agencies provide excellent training for applicants, evaluators and agency staff.

236 Some are in-person (or virtual) workshops with experts; some are dedicated websites, booklets, 237 videos and other similar resources. The most comprehensive open access training to date is by

238 CIHR and NIH. Each of these agencies provides on-line, interactive courses on health, medicine 239 and biomedical research. CIHR released three online trainings in 2015, entitled 'integrating sex 240 and gender into biomedical research', 'sex and gender in primary data collection with humans' 241 and 'sex and gender analysis of secondary data from human participants' ${ }^{45}$.

243 After a multi-year consultancy with numerous experts, NIH released four, interactive courses

244 designed to assist the biomedical research community — including researchers, grant applicants 245 and peer reviewers - account for and appropriately integrate SABV across the full spectrum of 246 biomedical sciences: the Health of Women and Men, Experimental Design, Analyses and 247 Research Reporting ${ }^{46}$. 
249 CIHR evaluated the effectiveness of their online trainings. The trainings themselves included a

250 pre-test and a post-test, which showed that $62 \%$ of participants who completed the basic science

251 module demonstrated improved knowledge, 84\% those completing the human data collection

252 module and $73 \%$ of those completing the secondary data analysis module demonstrated

253 improved knowledge of sex and gender analysis ${ }^{47}$.

255 Similar training materials are required for subjects not covered, such as engineering (e.g.

256 mechanical, civil and electrical), computer science (e.g. natural language processing, computer

257 vision and machine learning) marine science and environmental sciences. The EC supported the

258 Gendered Innovations Expert Groups in 2011-2013 and 2018-2020 to create case studies across

259 EC funding areas ${ }^{43,48}$. DFG has some introductory materials ${ }^{49}$. All Canadian Tri-Agency

260 materials are in English and French; Gendered Innovations has been translated in full or in part

261 into Chinese, French, German, Spanish and Swedish. Additional translations of training

262 materials would support researchers more globally. Agencies can coordinate and share trainings

263 internationally; there is no need to duplicate efforts, except where specific cultural needs require

264 a particular approach.

266 Most trainings are voluntary. However, some funders, CIHR for example, require applicants to 267 submit a certificate of completion for some large, strategic competitions. Use of the same 268 training materials by applicants, evaluators and agency staff helps ensure consistency in policies, 269 terminology and expectations. The EC and CIHR, however, found that evaluators valued 270 coaching tailored to their research area ${ }^{50,8}$. This training may be provided as part of the reviewer 271 induction process. For agency staff, some funders embed SG\&DA training requirements in the 272 agency's overall equality plans ${ }^{51}$.

274 Some agencies foster training in this area through research institutions. The NIH, for example, 275 has invested \$160 million in Specialized Centers of Research Excellence across 25 research 276 institutions to 'train researchers in experimental design and analyses that consider sex and/or 277 gender'. These research hubs also support the development of standards and policies for 278 analysing SABV and sex differences in biomedical research ${ }^{9}$. Professional societies and 
279 academies could support these efforts by integrating these topics into their licensing and

280 professional development materials.

\section{Evaluation of policy implementation}

283 Only three agencies in our study had performed policy implementation evaluations. A further

284 nine were in the planning stages; the majority had no plans in place. We strongly recommend

285 that agencies implement evaluation plans as they develop policies in order to facilitate

286 appropriate quantitative and qualitative evaluation.

We recommend a multi-part evaluation:

1. The number and proportion of grants that include SG\&DA. CIHR found that from 2011 to 2019 , the proportion increased from $22 \%$ to $83 \%$ for sex analysis and from $12 \%$ to $33 \%$ for gender analysis. The level of integration differed across sectors with the lowest in biomedical and the highest in clinical research ${ }^{8}$. An independent study of the NIH found that applicants who adequately addressed SABV in their experimental design, analysis and reporting rose from $51 \%$ in 2016 to $66 \%$ in $2017^{52}$.

2. The quality of SG\&DA in proposals. The EC conducted a mid-term evaluation of Horizon 2020 in 2017, including the quality of the gender dimension. They considered methods, impacts, dissemination and also whether the project had moved the gender dimension ahead in that field and could serve as a 'good practice.' They concluded that the quality of the gender dimension in project proposals was not high and that more training was needed ${ }^{10}$.

For agencies where SG\&DA is a separate question, policy evaluators may monitor the quality of reviewers' work by checking correlations between reviewers' scores and the quality of applicants' proposals ${ }^{53}$. This may also be used to measure evaluation quality across different funding streams.

CIHR built the assessment of the quality of SG\&DA in proposals into the review process. As noted above, CIHR requires evaluators to rate the sex and gender aspects of proposals 
and to provide a rationale for that rating ${ }^{8}$. Each application is evaluated by three independent evaluators; applications that receive the top score from at least two evaluators is considered high quality.

Qualitative analysis showed conflation of the terms sex and gender at both the EC and CIHR.

3. The quality of evaluators' scoring and comments. CIHR manually sampled $5 \%$ of evaluators' comments to check the quality of responses ${ }^{8}$.

The EC reviewed the effectiveness of review panels and found that only $36 \%$ considered the gender dimension and of those $70 \%$ included a gender expert, suggesting that review panels require guidance from experts ${ }^{10}$.

The EC experimented with computer-assisted textual analysis given the volume of applications per year ${ }^{10}$. These methods are in their infancy.

4. The number of applicants, evaluators and staff who engaged in trainings and what type of training. If possible, the correlation between trainings applicants attend and the success of proposals submitted post-training should be assessed. Some funders, such as the Spanish An external review of NIH found that, in 2017, 88\% of reviewers felt confident that they understood the SABV policy, but only $68 \%$ thought that SABV was important for all NIH funded research ${ }^{52}$. This study did not evaluate the quality of reviewers' evaluations. Carlos III Health Institute, reported in our questionnaire that they monitor the number of applicants who participate in SG\&DA training and are setting targets to improve this over time.

5. The number and proportion of peer-reviewed publications or other recognized modes of dissemination that result from grants that incorporated SG\&DA. To monitor this, funders will need to track papers and research outputs using grant numbers. Science Foundation 
Ireland (SFI) reported in our study that they collect researcher-reported publication data to check that proposals that included sex and/or gender analysis reported that dimension in publications. This will allow SFI scientific program managers to raise any concern at the mid-term award review.

Through their review process, CIHR found other correlations of note. Consistent with other literature ${ }^{54}$, CIHR discovered that women applicants are more likely to integrate sex and gender analysis into their proposals. Further, they found that applicants who scored well on the sex/gender question scored well overall, i.e. this improved the overall quality of the proposal, and applicants were more likely to get funded ${ }^{8}$.

SG\&DA policies are only as good as their outcomes, namely the impact on the research outputs. It was difficult to develop scoring mechanisms for this study that accurately correlate with impactful SG\&DA policies because so few funders have such policies in place and even fewer have evaluated those policies. While we have established essential elements of quality SG\&DA policies through our five-part policy roadmap, further quantitative and qualitative analysis is necessary to validate the scoring. This includes the weighting of the five sections to help understand which elements provide the best policy outcomes. However, all aspects of the scoring framework are necessary for a successful policy; none stands on its own.

\section{The Road Forward}

As an immediate next step, we will work with colleagues globally to provide a toolkit of best policies and practices to consider when implementing policy to be hosted by Gendered Innovations. As we continue to test our evaluation strategy, it may be appropriate to add sections to our policy roadmap. Agencies, for example, may support SG\&DA with different funded initiatives. In addition to their Centers of Excellence mentioned above, the NIH convened a key stakeholders workshop to develop methods and techniques to support SABV. They also provide a Sex/Gender Administrative Supplement to encourage researchers with ongoing NIH funding to integrate sex and gender analysis where it may still be lacking. Finally, they issue calls for proposals in areas that require more research, such as analysing how sex and gender interact in 
371 health outcomes ${ }^{9}$. Similarly, the EC will offer funding to gender studies and intersectional 372 research to support SG\&DA ${ }^{28}$.

374 A trend we continue to watch is the broadening of sex and gender analysis to include other social 375 dimensions. Already, the EC has added 'intersectional' analysis to their Gender Dimension; 376 these policies, however, remain under the broader Gender Equality strategy. The DFG started 377 with sex, gender and 'diversity' on equal terms. The NIH has included 'age', which they term 378 'Inclusion across the Lifespan'. A number of funding agencies, such as NSERC, have signaled 379 that they incorporate research design policies under a broader Equity, Diversity and Inclusion 380 (EDI) umbrella ${ }^{44}$. This change in terminology reflects the overarching objectives of NSERC to 381 incorporate wider aspects of diversity into the research process. In the past, EDI has typically 382 focused on 'who' is doing the research not 'how' research is done, meaning that special care will 383 be needed to expand EDI to include research methodologies.

385 Publicly funded research agencies began implementing SG\&DA policies in the 2000s. The goal 386 of our study has been to evaluate those policies and practices, while being sensitive to unique 387 regulatory and cultural research ecosystems. Our five-part SG\&DA policy roadmap (Fig. 1) is 388 designed to lay out key elements for effective policy in this area. Effective SG\&DA policy is not 389 a single question added to instructions to applicants, but consists of quality definitions of terms, 390 proposal guidelines for applicants, instructions for evaluators, training for applicants, evaluators 391 and staff, and evaluation of policy implementation. This project provides agencies with a 392 roadmap of best practices globally for promoting rigorous, reproducible and equitable research.

393 Through this process, we seek to ensure international standards of research excellence.

395 Acknowledgements We thank the members of our advisory board for their guidance. We thank 396 the participating funding agencies for their time.

398 Author Contributions: LH and LS developed all materials, administered the questionnaire, 399 scored results, conceptualised and wrote the paper. LH created the visualisations. 
403 Supplementary Information is available for this paper.

\section{References}

1. Tannenbaum, C., Ellis, R. P., Eyssel, F., Zou, J. \& Schiebinger, L. Sex and gender analysis improves science and engineering. Nature 575, 137-146 (2019).

2. Directorate-General of Research and Technological Development Unit 5: Women and Science. Gender Mainstreaming in the 6th Framework Programme-Reference Guide for Scientific Officers/Project Officers. (European Commission Brussels, 2003).

3. Thande, N. K., Wang, M., Curlin, K., Dalvie, N. \& Mazure, C. M. The Influence of Sex and Gender on Health: How Much Is Being Taught in Medical School Curricula? J. Womens Health 2002 28, 1748-1754 (2019).

4. Schiebinger, L., Klinge, I., Sánchez de Madariaga, I., Paik, H. Y., Schraudner, M., and Stefanick, M. Sex and Gender Analysis Policies of Peer-Reviewed Journals. Gendered Innovations http://genderedinnovations.stanford.edu/sex-and-gender-analysis-policies-peerreviewed-journals.html (2021).

5. Merriman, R. et al. The gender and geography of publishing: a review of sex/gender reporting and author representation in leading general medical and global health journals. BMJ Glob. Health 6, e005672 (2021).

6. The Lancet. Information for Authors. (The Lancet, 2021).

7. Nature Portfolio. Editorial Policies: Ethics and biosecurity. Nature Portfolio https://www.nature.com/nature-portfolio/editorial-policies/ethics-and-biosecurity\#ethicspolicy (2021).

8. Haverfield, J. \& Tannenbaum, C. A 10-year longitudinal evaluation of science policy interventions to promote sex and gender in health research. Health Res. Policy Syst. 19, 94 (2021).

9. Arnegard, M. E., Whitten, L. A., Hunter, C. \& Clayton, J. A. Sex as a Biological Variable: A 5-Year Progress Report and Call to Action. J. Womens Health 2002 29, 858-864 (2020). 
431 10. Directorate-General for Research and Innovation (European Commission). Interim

432 evaluation: gender equality as a crosscutting issue in Horizon 2020. (Publications Office of 433 the European Union, 2017).

434 11. Sex and Gender Sensitive Research Call to Action Group, Wainer, Z. \& Carcel, C. Sex and 435 gender in health research: updating policy to reflect evidence. Med. J. Aust. 212, 57-62.e1 436 (2020).

437 12. White, J., Tannenbaum, C., Klinge, I., Schiebinger, L. \& Clayton, J. The Integration of Sex 438 and Gender Considerations Into Biomedical Research: Lessons From International Funding 439 Agencies. J. Clin. Endocrinol. Metab. 106, 3034-3048 (2021).

440 13. GRC Gender Working Group. Gender-Disaggregated Data at the Participating

$441 \quad$ Organisations of the Global Research Council: Results of a global survey. (Global Research 442 Council, 2021).

443 14. Håkansson, S. Y. \& Sand, J. The Gender Dimension in Research and Innovation: Results 444 from a global survey on research funding organisations. (Swedish Secretariat for Gender 445 Research University of Gothenburg, 2021).

446 15. Schiebinger, L., Klinge, I., Sánchez de Madariaga, I., Paik, H. Y., Schraudner, M., and 447 Stefanick, M. Sex and Gender Analysis Policies of Major Granting Agencies. Gendered 448 Innovations https://genderedinnovations.stanford.edu/sex-and-gender-analysis-policies449 major-granting-agencies.html (2021).

450 16. Australian Government. Australian Government Guidelines on the Recognition of Sex and 451 Gender. (2015).

452 17. Government of Canada. Gender-Based Analysis Plus (GBA+) at CIHR. Canadian Institutes 453 of Health Research https://cihr-irsc.gc.ca/e/50968.html (2018).

454 18. Gouvernement du Canada. L'analyse comparative entre les sexes plus (ACS+) aux IRSC. $455 \quad$ Instituts de recherche en santé du Canada https://cihr-irsc.gc.ca/f/50968.html (2018).

456 19. Natural Sciences and Engineering Research Council of Canada. Guide for Applicants: 457 Considering equity, diversity and inclusion in your application. (2017).

458 20. Conseil de recherches en sciences naturelles et en génie du Canada. Guide du candidat : 459 Tenir compte de l'équité, de la diversité et de l'inclusion dans votre demande. (2017). 
21. Government of Canada. Government of Canada's approach on Gender-based Analysis Plus. Women and Gender Equality Canada https://women-gender-equality.canada.ca/en/genderbased-analysis-plus/government-approach.html (2021).

22. Gouvernement du Canada. Approche du gouvernement du Canada sur l'analyse comparative entre les sexes plus. https://femmes-egalite-genres.canada.ca/fr/analyse-comparative-entresexes-plus/approche-gouvernement.html (2021).

23. Schiebinger, L., Klinge, I., Sánchez de Madariaga, I., Paik, H. Y., Schraudner, M., \& Stefanick, M. Terminology. Gendered Innovations https://genderedinnovations.stanford.edu/terms.html (2021).

24. Office of Research on Women's Health. Sex \& Gender. NIH Office of Research on Women's Health https://orwh.od.nih.gov/sex-gender (2021).

25. Government of Canada. What is gender? What is sex? Canadian Institutes of Health Research https://cihr-irsc.gc.ca/e/48642.html (2014).

26. Bauer, G. Questions to Guide Quantitative Intersectional Analyses. CIHR Institute of Gender and Health: Meet the methods series vol. 2 (2021).

27. Bauer, G. Quantitative Intersectional Study Design and Primary Data Collection. CIHR Institute of Gender and Health: Meet the methods series vol. 1 (2021).

28. EU Grants. Horizon Europe (HORIZON): Programme Guide. (November 2021).

29. Clayton, J. A. Studying both sexes: a guiding principle for biomedicine. FASEB J. Off. Publ. Fed. Am. Soc. Exp. Biol. 30, 519-524 (2016).

30. Tannenbaum, C., Schwarz, J. M., Clayton, J. A., de Vries, G. J. \& Sullivan, C. Evaluating sex as a biological variable in preclinical research: the devil in the details. Biol. Sex Differ. 7, 13 (2016).

31. National Institutes of Health (NIH). NIH Policy and Guidelines on the Inclusion of Women and Minorities as Subjects in Clinical Research. NOT-OD-18-014 (2017).

32. National Institutes of Health (NIH). Inclusion of Women and Minorities as Participants in Research Involving Human Subjects. NIH Grants \& Funding https://grants.nih.gov/policy/inclusion/women-and-minorities.htm (2021).

33. National Institutes of Health (NIH). NIH Policy and Guidelines on the Inclusion of Individuals Across the Lifespan as Participants in Research Involving Human Subjects. NOT-OD-18-116 (2017). 
34. German Research Foundation (DFG) Equal Opportunities, Research Integrity and CrossProgramme Development Division. Guidelines for Safeguarding Good Research Practice: Code of Conduct. (2019).

35. German Research Foundation (DFG). Mission Statement. $D F G$ https://www.dfg.de/en/dfg_profile/mission/index.html (2018).

36. Government of Japan. Science, Technology and Innovation: The 6th Basic Plan. (Government of Japan, 2021).

37. Government of Japan. Science, Technology and Innovation: The 5th Basic Plan. (Government of Japan, 2016).

38. Ministry of Science and ICT, Republic of Korea National Assembly. Science and Technology Framework Act. 17671 (2021).

39. Irish Research Council. Irish Research Council Government of Ireland (GOI) Postdoctoral Fellowship: Guide for Applicants. (2021).

40. Science Foundation Ireland. Guidance for Applicants on Ethical and Scientific Issues. (2019).

41. The Netherlands Organisation for Health Research and Development. FAQ gender in onderzoek. ZonMw https://www.zonmw.nl/nl/over-zonmw/diversiteit/gender-engezondheid/faq-gender-in-onderzoek/ (2021).

42. Deutsche Forschungsgemeinschaft. Proposal Preparation Instructions: Project Proposals. https://www.dfg.de/formulare/54_01/54_01_en.pdf (2021).

43. Directorate-General for Research and Innovation (European Commission). Gendered innovations 2: how inclusive analysis contributes to research and innovation: policy review. (Publications Office of the European Union, 2020).

44. Government of Canada. Natural Sciences and Engineering Research Council of Canada (NSERC) - Equity, diversity and inclusion considerations at each stage of the research process. NSERC https://www.nserc-crsng.gc.ca/NSERC-CRSNG/PoliciesPolitiques/EDI_guidance-Conseils_EDI_eng.asp (2021).

45. Institute of Gender and Health. Online Training Modules: Integrating Sex \& Gender in Health Research. Canadian Institutes of Health Research https://cihr-irsc.gc.ca/e/49347.html (2015). 
521 46. Office of Research on Women's Health. Sex as a Biological Variable: A Primer. NIH Office 522 of Research on Women's Health https://orwh.od.nih.gov/career-development-education/e-

523 learning/sabv-primer (2021).

524 47. Tannenbaum, C. \& van Hoof, K. Effectiveness of online learning on health researcher 525 capacity to appropriately integrate sex, gender, or both in grant proposals. Biol. Sex Differ. 9, $526 \quad$ (2018).

527 48. Schiebinger, L., Klinge, I., Sánchez de Madariaga, I., Paik, H. Y., Schraudner, M., \&

$528 \quad$ Stefanick, M. Engineering and Technology Case Studies. Gendered Innovations

529 https://genderedinnovations.stanford.edu/case-studies-engineering.html (2021).

530 49. Deutsche Forschungsgemeinschaft (DFG, German Research Foundation). Relevance of Sex, $531 \quad$ Gender and Diversity in Research. $D F G$

532 https://www.dfg.de/en/research_funding/principles_dfg_funding/diversity_dimensions/index $533 \quad . h t m l(2021)$.

534 50. Directorate-General for Research and Innovation (European Commission). Gendered 535 innovations : how gender analysis contributes to research : report of the expert group 536 'Innovation through gender'. (Publications Office of the European Union, 2013).

537 51. AEI Strategic Group on Gender Equality. I GENDER EQUALITY PLAN 2021- 2023 of the 538 Agencia Estatal de Investigación (State Research Agency of Spain) for R\&D\&I funding 539 activities. (2021).

540 52. Woitowich, N. C. \& Woodruff, T. K. Implementation of the NIH Sex-Inclusion Policy:

541 Attitudes and Opinions of Study Section Members. J. Womens Health 2002 28, 9-16 (2019).

542 53. Science Foundation Ireland. SFI Frontiers for the Future Programme 2021: Call for 543 Submission of Proposals. (Science Foundation Ireland, 2021).

544 54. Nielsen, M., Andersen, J. P., Schiebinger, L. \& Schneider, J. One and a half million medical 545 papers reveal a link between author gender and attention to gender and sex analysis. Nat.

546 Hum. Behav. 1, (2017). 